\title{
Structural and Optical Properties of Struvite. Elucidating Structure of Infrared Spectrum in High Frequency Range
}

\author{
Dominik Sidorczuk, Marcin Kozanecki, Bartolomeo Civalleri, Katarzyna Pernal, and Jolanta Prywer*
}

Cite This: J. Phys. Chem. A 2020, 124, 8668-8678

Read Online

ABSTRACT: Study of structure and optical properties of magnesium ammonium phosphate hexahydrate crystal known as struvite is presented. Experimentally determined infrared (IR) and ultraviolet-visible (UV-vis) spectra are compared with the theoretical predictions of density functional methods. Examination of the interatomic bond lengths, Mulliken atomic charges, and binding energies of water in the magnesium hexahydrate cation, together with the analysis of the hydrogen bond pattern have allowed us to explain a special feature of the IR spectrum of struvite, a blueshift of the band corresponding to the $\mathrm{O}-\mathrm{H}$ stretching mode. This mode has been assigned to a "dangling" hydroxyl group in one of the water molecules in magnesium

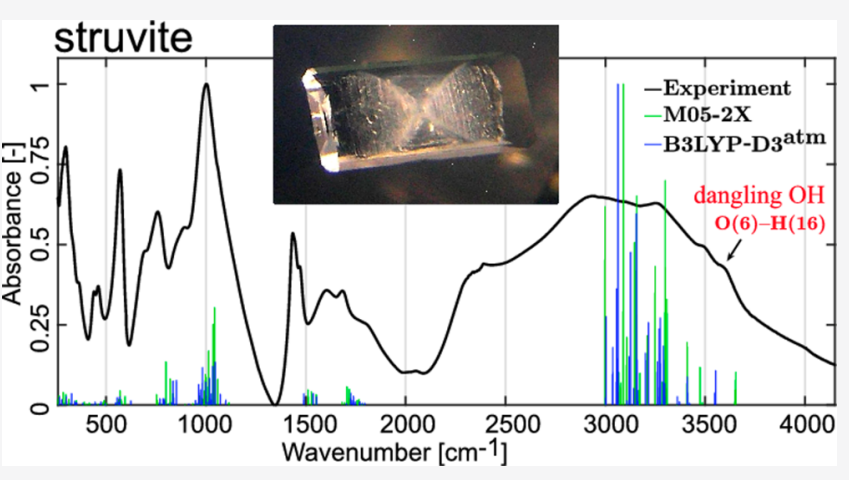
hexahydrate. Using experimentally obtained UV-vis spectrum and performing Tauc plots analysis, optical bandgap of struvite has been narrowed to a range from 5.92 to $6.06 \mathrm{eV}$.

\section{INTRODUCTION}

Magnesium ammonium phosphate hexahydrate, $\mathrm{MgNH}_{4} \mathrm{PO}_{4}$. $6 \mathrm{H}_{2} \mathrm{O}$, known as struvite, has been widely investigated over the past decade for several reasons. First, struvite can be a problem in sewage and wastewater treatment as it precipitates easily on specific locations, which may clog the system pipes. ${ }^{1-5}$ On the other hand, struvite is a potential source of phosphorus, nitrogen, and magnesium, and therefore it is the main compound recovered from wastewater and recycled as a useful $\mathrm{P}-\mathrm{N}-\mathrm{Mg}$-containing fertilizer. ${ }^{6,7}$ The recovery of struvite from wastewater is especially essential in view of phosphorus, because nowadays natural sources of heavy metal-free phosphorus are becoming scarce. ${ }^{3}$ At the same time, phosphorus content in sewage sludge is a growing environmental concern. However, the main reason for which physicochemical properties of struvite are examined results from the fact that it constitutes the main component of the so-called infectious urinary stones representing up to $30 \%$ of all urinary stones. ${ }^{8}$ Studies show that in highly developed countries, the incidence of infectious urolithiasis is steadily increasing, indicating that infectious urinary stones are a social problem. The infection is the result of the activity of microorganisms producing urease, mainly from Proteus species. ${ }^{9}$ Struvite stones may grow rapidly over a period of weeks to months and, if not adequately treated, can develop into a large stone that fills the entire intrarenal collecting system. Patients with infectious stones who receive no treatment have about a $50 \%$ chance of losing a kidney. ${ }^{10}$

The above arguments illustrate that struvite is a crystalline material of high importance in different fields of human activity and there is a need for investigating and understanding its properties at atomistic level. The aim of this work is to study selected properties of struvite by combining theoretical and experimental tools. In particular, we present experimental predictions for covalent bond lengths in complexes building struvite and compare them against the theoretically obtained ones. For the latter, density functional theory (DFT) methods are used. We also investigate hydrogen interactions governing the structure of struvite and strongly affecting its vibrational spectrum. The experimental infrared (IR) spectrum is shown and its unusual features, specific for struvite, are explained by relying on the theoretically predicted vibrational modes. Finally, the ultraviolet-visible (UV-vis) spectrum of struvite is presented and used to obtain one of the most accurate, according to our best knowledge, estimation of its energy bandgap.

\section{MATERIALS AND METHODS}

Struvite crystals were synthesized in sodium metasilicate gel by single diffusion gel growth technique. All used chemicals of reagent-grade purity were purchased from Sigma-Aldrich. To prepare a gel the following compounds were used: sodium metasilicate $\left(\mathrm{Na}_{2} \mathrm{SiO}_{3}\right.$, abbreviation SMS), ammonium dihy-

Received: May 25, 2020

Revised: September 22, 2020

Published: September 24, 2020

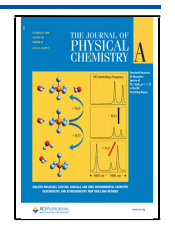


drogen phosphate $\left(\mathrm{NH}_{4} \mathrm{H}_{2} \mathrm{PO}_{4}\right.$, abbreviation $\left.\mathrm{ADP}\right)$ and magnesium acetate tetrahydrate $\left(\left(\mathrm{CH}_{3} \mathrm{COO}\right)_{2} \mathrm{Mg} \cdot 4 \mathrm{H}_{2} \mathrm{O}\right)$. The chemicals were dissolved in distilled water. An aqueous $0.5 \mathrm{M}$ solution of ADP and SMS solution of specific gravity 1.07 were mixed together in appropriate amounts to adjust the $\mathrm{pH}$ of the mixture equal to 7.0. Such prepared mixture was poured into tubes of $19 \mathrm{~cm}$ in length and $3 \mathrm{~cm}$ in diameter and left at room temperature for gelation for $24 \mathrm{~h}$. Next, $25 \mathrm{~mL}$ of $1 \mathrm{M}$ magnesium acetate tetrahydrate aqueous solution was gently poured on the surface of newly formed gel in respective tubes and closed with airtight cover. The crystal growth usually lasted from 3 to 4 weeks. After this time, the struvite crystals reach a size of about $1 \mathrm{~cm}$ along the $b$-axis, see Figure 1 for a picture presenting an illustrative example of a crystal grown in our laboratory, following the above-described procedure.

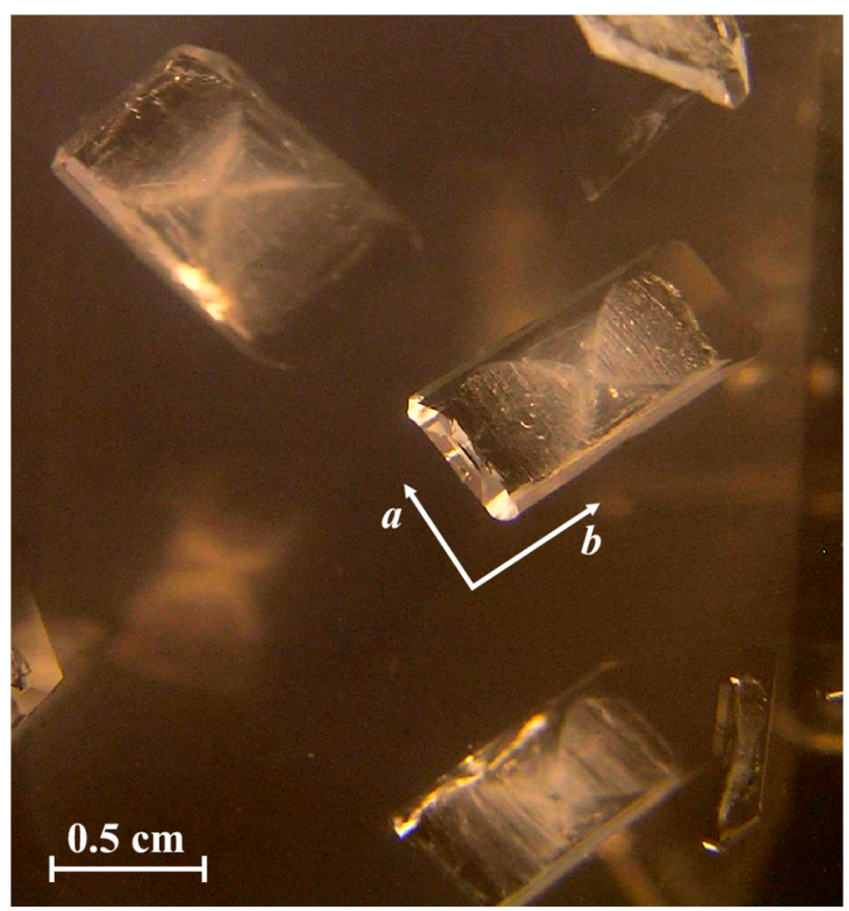

Figure 1. Struvite crystals grown in gel medium.

Absorption spectra in the near, middle, and far IR regions were measured for pellets that were prepared as follows. Struvite crystals were finely ground in an agate mortar, and then $\mathrm{KBr}$ dried under vacuum at $110^{\circ} \mathrm{C}$ for $24 \mathrm{~h}$ was added. $\mathrm{KBr}$ was used as a carrier for the sample because it is optically transparent for the light in the infrared range. The weight of struvite accounted for $30 \%$ of the sample weight. The prepared sample was placed in a pellet die and compressed using $6 \mathrm{ton} / \mathrm{cm}^{2}$ force for $10 \mathrm{~min}$ at room temperature. Absorption spectra in the near, middle and far-infrared regions were collected at room temperature with the use of a Fourier transform infrared (FTIR) spectrometer (Nicolet iS50, Thermo Fisher Scientific) in transition mode. The spectrum of the pristine $\mathrm{KBr}$ was measured as blank sample and then, after normalization, subtracted from the spectrum of struvite dispersed in $\mathrm{KBr}$. This procedure was applied as the used FTIR spectrometer is a single-beam instrument. The spectral resolution was $2 \mathrm{~cm}^{-1}$ and 32 scans were averaged.

The UV-vis spectra were measured for struvite single crystals in the range of $200-800 \mathrm{~nm}$. They were acquired at room temperature with the use of Cary $5000 \mathrm{UV}$-vis spectrometer (Varian/Agilent). The standard double beam, transmission mode was used. The struvite crystal was placed in the sample compartment in solid state holder with the diaphragm with aperture diameter equal $5 \mathrm{~mm}$. The spectra were recorded in relation to empty holder as a reference and identical diaphragm was introduced into the reference beam. The following experimental conditions were used: integrating time $0.1 \mathrm{~s} /$ point, spectral width $2 \mathrm{~nm}$ and scan rate $300 \mathrm{~nm} / \mathrm{min}$.

To merge the measured IR and UV-vis spectra into one curve, the following procedure was applied. A polynomial baseline was extracted from each spectrum separately. Next, all spectra were normalized by signal multiplication to overlap the curves in the common spectral range. Thus, the absorbance is represented in the relative, not absolute, unites. The final spectrum is presented in section 5 in a wavenumber representation.

\section{COMPUTATIONAL DETAILS}

The structural properties of the struvite crystal, in particular the lattice constants (Table 1), bond lengths (Table 2), Mulliken atomic charges (Table 3), binding energies (Table 4), and the infrared spectrum (Figure 3), have been obtained using the CRYSTAL17 code. ${ }^{11,12}$ For all atoms we used the triple- $\zeta$ basis sets given for phosphorus, magnesium, and hydrogen in ref 13 and for oxygen and nitrogen atoms in ref 14.

The full struvite crystal geometry optimization was carried out through analytical energy gradient calculations with respect to the atomic positions in the unit cell and using the quasi-Newton method in combination with the BFGS algorithm for Hessian. $^{3,12}$ We adapted the default CRYSTAL17 geometry criteria for structure optimization and in calculation of the IR spectrum. The energy convergence threshold was set to $10^{-8}$ and $10^{-11}$ Hartree for structure optimization and IR vibration calculations, respectively. The criterion for bielectron integrals i.e. Coulomb and exchange integrals for an infinite lattice is controlled by the TOLINTEG keyword with the parameters set to $10^{-7}, 10^{-7}, 10^{-7}, 10^{-9}$, and $10^{-20}$. The reciprocal space was sampled by the Monkhorst-Pack k-type method ${ }^{15}$ with a shrinking factor equal to 7 , which corresponds to $64 \mathrm{k}$ points in the irreducible Brillouin zone. The three-dimensional integra-

Table 1. Comparison of Theoretically Obtained Lattice Constants $[\AA]$ and Unit Cell Volume $\left[\AA^{3}\right]$ with the Experimental Data (Exp.) Taken from Ref $43^{a}$

\begin{tabular}{lcccccc} 
& exp. & M05-2X & B3LYP-D3 & & M06-L & \multicolumn{1}{c}{ HSE06-D3 $^{\text {atm }}$} \\
$a$ & 6.965 & 6.950 & 6.954 & 6.940 & 7.002 \\
$b$ & 6.117 & 6.097 & 6.058 & 6.085 & 6.112 \\
$c$ & 11.206 & 11.211 & 11.197 & 11.153 & 11.273 \\
volume & 477.37 & 475.04 & 471.63 & 471.02 & 482.45 \\
MUE & & 0.014 & 0.026 & 0.036 & 469.10 & 0.036
\end{tabular}

${ }^{a}$ MUE denotes a mean unsigned error computed for the lattice constants with respect to the experimental values. 
Table 2. Atom-Atom Distances $[\AA]$ and Experimental (Exp.) Bond Lengths between Heavy Atoms Taken from Ref $43^{a}$

\begin{tabular}{|c|c|c|c|c|c|}
\hline \multirow{2}{*}{\multicolumn{2}{|c|}{$\begin{array}{c}\text { bound atoms and } \\
\text { their labels }\end{array}$}} & \multicolumn{3}{|c|}{ struvite crystal } & \multirow{2}{*}{$\frac{\text { isolated species }^{b}}{\text { M05-2X }}$} \\
\hline & & \multirow[t]{2}{*}{ exp. } & \multirow[t]{2}{*}{ M05-2X } & \multirow[t]{2}{*}{ B3LYP-D3 ${ }^{\text {atm }}$} & \\
\hline $\mathrm{Mg}$ & $\mathrm{O}$ & & & & \\
\hline \multirow[t]{4}{*}{1} & $2(3)$ & 2.051 & 2.050 & 2.053 & 2.075 \\
\hline & $4(5)$ & 2.075 & 2.074 & 2.078 & \\
\hline & 6 & 2.107 & 2.104 & 2.105 & \\
\hline & 7 & 2.109 & 2.117 & 2.135 & \\
\hline $\mathrm{O}$ & $\mathrm{H}$ & & & & \\
\hline \multirow[t]{2}{*}{$2(3)$} & $8(10)$ & 0.978 & 0.987 & 0.991 & 0.965 \\
\hline & $9(11)$ & 0.992 & 0.997 & 0.998 & \\
\hline \multirow[t]{2}{*}{$4(5)$} & $12(14)$ & 0.985 & 0.993 & 0.996 & \\
\hline & $13(15)$ & 1.001 & 0.997 & 1.000 & \\
\hline \multirow[t]{2}{*}{6} & 16 & 0.952 & 0.972 & 0.978 & \\
\hline & 17 & 0.991 & 0.992 & 0.992 & \\
\hline \multirow[t]{2}{*}{7} & 18 & 0.986 & 0.994 & 0.997 & \\
\hline & 19 & & & & \\
\hline $\mathrm{P}$ & $\mathrm{O}$ & & & & \\
\hline \multirow[t]{3}{*}{20} & 21 & 1.551 & 1.563 & 1.570 & 1.600 \\
\hline & $22(23)$ & 1.544 & 1.562 & 1.567 & \\
\hline & 24 & 1.547 & 1.567 & 1.570 & \\
\hline $\mathrm{N}$ & $\mathrm{H}$ & & & & \\
\hline \multirow[t]{3}{*}{25} & 26 & 1.008 & 1.024 & 1.026 & 1.022 \\
\hline & $27(28)$ & 0.993 & 1.028 & 1.033 & \\
\hline & 29 & 1.052 & 1.040 & 1.046 & \\
\hline MUE & & & 0.009 & 0.012 & \\
\hline
\end{tabular}

${ }^{a}$ For bonds involving hydrogen atoms, data from neutron diffraction experiment reported in ref 31 is used. Labels assigned to atoms correspond to Figure 2. Labels in parentheses correspond to atoms which are symmetry-equivalent to atoms in the same row in the table. MUE (mean unsigned error) of theoretically predicted bond lengths computed with respect to experimental values. ${ }^{b}$ Bond lengths obtained from geometry optimization of the isolated $\mathrm{Mg}\left(\mathrm{H}_{2} \mathrm{O}\right)_{6}{ }^{2+}$, $\mathrm{PO}_{4}{ }^{3-}$, and $\mathrm{NH}_{4}{ }^{+}$species with the M05-2X functional.

Table 3. Mulliken Atomic Charges on Atoms in the $\mathrm{Mg}\left(\mathrm{H}_{2} \mathrm{O}\right)_{6}{ }^{2+}$ Complex in the Struvite Crystal and the Isolated Complex ${ }^{a}$

\begin{tabular}{llccc} 
& & & \multicolumn{2}{c}{ isolated complex } \\
\cline { 4 - 5 } atom & label & struvite crystal & crystal geom. & opt. geom. \\
$\mathrm{Mg}$ & 1 & 1.68 & 1.63 & 1.66 \\
$\mathrm{O}$ & $2(3)$ & -0.83 & -0.70 & -0.71 \\
$\mathrm{H}$ & $8(10)$ & 0.39 & 0.39 & 0.38 \\
& $9(11)$ & 0.38 & 0.38 & \\
$\mathrm{O}$ & $4(5)$ & -0.83 & -0.69 & -0.71 \\
$\mathrm{H}$ & $12(14)$ & 0.38 & 0.37 & 0.38 \\
& $13(15)$ & 0.39 & 0.38 & \\
$\mathrm{O}$ & 6 & -0.79 & -0.72 & -0.71 \\
$\mathrm{H}$ & 16 & 0.37 & 0.37 & 0.38 \\
& 17 & 0.40 & 0.40 & \\
$\mathrm{O}$ & 7 & -0.84 & -0.71 & -0.71 \\
$\mathrm{H}$ & 18 & 0.39 & 0.38 & 0.38 \\
& 19 & 0.39 & 0.38 &
\end{tabular}

${ }^{a}$ In the latter case the calculations were performed in the frozen crystal geometry ("crystal geom." column) and the geometry optimized for the isolated complex ("opt. geom." column). All calculations have been performed with the M05-2X functional. Labels in the parentheses correspond to atoms which are symmetryequivalent to atoms in the same row in table.
Table 4. Binding Energies $[\mathrm{kcal} / \mathrm{mol}]$ of Water Molecules in $\mathrm{Mg}\left(\mathrm{H}_{2} \mathrm{O}\right)_{6}{ }^{2+}$ Obtained for the Struvite Crystal (M05-2X Calculations) and the Isolated Complex (M05-2X and DFTSAPT Calculations) ${ }^{a}$

\begin{tabular}{|c|c|c|c|c|}
\hline \multirow{2}{*}{$\begin{array}{c}\text { label of oxygen } \\
\text { atom }\end{array}$} & \multirow{2}{*}{$\begin{array}{c}\text { struvite } \\
\text { crystal }\end{array}$} & \multicolumn{2}{|c|}{ isolated complex } & \multirow{2}{*}{$\begin{array}{c}\begin{array}{c}\text { H-bonds } \\
\text { energy }\end{array} \\
\text { M05-2X }\end{array}$} \\
\hline & & M05-2X & DFT-SAPT & \\
\hline $2(3)$ & 45.4 & 32.4 & 27.8 & 13.0 \\
\hline $4(5)$ & 47.6 & 31.8 & 27.4 & 15.9 \\
\hline 6 & 42.5 & 35.1 & 30.3 & 7.4 \\
\hline 7 & 46.6 & 31.6 & 26.3 & 15.0 \\
\hline
\end{tabular}

${ }^{a_{T}}$ The last column presents estimation of the total H-bond energies of a water molecules (labels of oxygen atoms corresponding to water molecules are shown in the first column).

tion grid is created by combining one-dimensional grid generated from the Gauss-Legendre radial quadrature method and the two-dimensional Lebedev angular point distribution. The grid parameters used in calculations are presented in the Supporting Information.

Computations for the isolated complexes (Tables 2-4) have been performed with the CRYSTAL17 code in the same basis set as that used for crystal calculations. The energy convergence criterion in self-consistent field calculations was set to $10^{-9}$ Hartree. Thresholds in geometry optimization for the gradient and atomic displacements were set to $3 \times 10^{-5}$ and $1.2 \times 10^{-4}$ bohr, respectively. The parameters for the TOLINTEG keyword were $10^{-20}, 10^{-20}, 10^{-20}, 10^{-20}$, and $10^{-20}$. The grid parameters used in molecular calculations are presented in the Supporting Information.

Calculations of the vibration frequency of individual modes are based on the harmonic approximation. Second order derivative is computed numerically using a two-point central differential for each coordinate. The calculation of the IR intensity for basic vibrations was calculated using the Berry phase method. ${ }^{16,17}$

The DFT symmetry adapted perturbation theory (DFTSAPT $)^{18-22}$ binding energies presented in Table 4 have been obtained using the MOLPRO2012 package. $^{23}$ The aug-ccpVDZ basis set $^{24,25}$ has been employed. For the gradientregulated asymptotic correction (GRAC) ${ }^{26}$ the $\mathrm{PBEO}^{27} \mathrm{HOMO}$ energy value was used. The ionization energies of $\mathrm{Mg}\left(\mathrm{H}_{2} \mathrm{O}\right)_{5}{ }^{2+}$ complex (computed by means of the local density-fitted UCCSD(T) method $^{28}$ with aug-cc-PV5Z/jkfit basis set ${ }^{29}$ ) was set to 0.8475 Hartree, while for $\mathrm{H}_{2} \mathrm{O}$ molecule it was set to 0.4638 Hartree. $^{30}$

\section{INSIGHTS INTO COVALENT AND HYDROGEN BONDING PATTERN IN STRUVITE FROM THEORETICAL PREDICTIONS}

With the aim of understanding changes in covalent bond lengths in molecules forming struvite in comparison with isolated species and to elucidate hydrogen bonds (H-bonds) structure, density functional calculations have been performed. Since struvite is composed of closed shell molecules which are either charged or polar, its crystal structure is determined by electrostatic interaction and hydrogen bonds. ${ }^{31}$ Density functional methods used in calculations should provide accurate description of noncovalent interactions in order to yield reliable predictions for the structure and properties of struvite. In order to select suitable density functionals, two groups of preselected 
functionals have been employed to compute unit cell parameters and compare them with experimental values. One group includes density functionals the exchange and correlation components of which were parametrized on, among others, training set of noncovalent interactions. Three functionals from this group were considered: M05-2X, ${ }^{32} \mathrm{M} 06-\mathrm{L},{ }^{33}$ and $\omega \mathrm{B} 97-$ $\mathrm{X}^{34}$ The second group includes $\mathrm{B}^{3} \mathrm{LYP}^{35}$ and $\mathrm{HSEN}^{36}$ functionals with $\mathrm{D}^{\text {atm }}$ correction. The latter consists of a pairwise atomic dispersion correction $\mathrm{D} 3^{37}$ with Becke-Johnson damping, ${ }^{38-40}$ and the Axilrod-Teller-Muto (atm) three-body interaction term. ${ }^{41,42}$ The computed lattice constants presented in Table 1 are compared with the highly accurate experimental data obtained from single-crystal X-ray diffraction (XRD) measurements carried out at a temperature of $90 \mathrm{~K}^{43}$ It should be mentioned that the crystal structure of struvite has been also determined by Whitaker et al., ${ }^{44}$ Abbona et al., ${ }^{45}$ and Tansman et al. ${ }^{46}$ by analyzing single-crystal X-ray diffraction data collected at room temperature. In addition, Ferraris et al. ${ }^{31}$ reported the structure of struvite, including position of hydrogen atoms, from neutron diffraction data.

It can be seen in Table 1 that functionals from both groups predict lattice constants of struvite in a good agreement with experimental values. The lowest mean unsigned error (MUE) for the lattice constants is achieved with the M05-2X and B3LYP-D3 ${ }^{\text {atm }}$ functionals. In particular, in the case of M05-2X the predicted unit cell parameters stay in a remarkably close agreement with the experimental values, the deviations not exceeding $0.02 \AA$.

The M05-2X and B3LYP-D3 ${ }^{\text {atm }}$ functionals perform accurately also in predicting bond lengths in molecules that struvite is comprised of, i.e. $\mathrm{Mg}-\mathrm{O}$ and $\mathrm{O}-\mathrm{H}$ distances in the hydrated magnesium cation complex $\mathrm{Mg}\left(\mathrm{H}_{2} \mathrm{O}\right)_{6}{ }^{2+}, \mathrm{P}-\mathrm{O}$ distances in the phosphate anion $\mathrm{PO}_{4}{ }^{3-}$, and $\mathrm{N}-\mathrm{H}$ bond lengths in $\mathrm{NH}_{4}{ }^{+}$cation. Bond lengths following from full geometry optimization of struvite crystal by employing either M05-2X or B3LYP-D3 ${ }^{\text {atm }}$ methods shown in Table 2 are confronted with the experimental values for $\mathrm{Mg}-\mathrm{O}$ and $\mathrm{P}-\mathrm{O}$ distances, ${ }^{43}$ and $\mathrm{O}-\mathrm{H}$ and $\mathrm{N}-\mathrm{H}$ distances. ${ }^{31}$ Notice that the numeric labels assigned to atoms presented in all tables in this work are depicted in Figure 2. Both M05-2X and B3LYP-D3 ${ }^{\text {atm }}$ functionals predict bond lengths in a good agreement with the experimental values, the mean unsigned errors of the computed values with respect to the experimental ones amounting to only $0.01 \AA$ for both functionals. The ordering of the $\mathrm{Mg}-\mathrm{O}$ bond lengths is correctly predicted by both functionals. By comparing computationally obtained $\mathrm{Mg}-\mathrm{O}$ bond lengths in the struvite crystal and in the isolated $\mathrm{Mg}\left(\mathrm{H}_{2} \mathrm{O}\right)_{6}{ }^{2+}$ complex one notices that $\mathrm{Mg}-\mathrm{O}(6)$ and $\mathrm{Mg}-\mathrm{O}(7)$ bonds are longer in the crystal than in the isolated molecule. A comparison of the $\mathrm{O}-\mathrm{H}$ bond lengths predicted by the M05-2X functional for crystal and the isolated species reveals that, as expected, most $\mathrm{O}-\mathrm{H}$ bonds are elongated comparing to their counterparts in water molecules surrounding $\mathrm{Mg}$ atom in the isolated complex. Bond elongation is a clear indication that in crystal the hydrogen atoms are $\mathrm{H}$-bond donors. It is noticeable, however, that one $\mathrm{O}-\mathrm{H}$ bond length, connecting $\mathrm{O}(6)$ and $\mathrm{H}(16)$ atoms, is significantly shorter than the other ones and it is almost the same as the $\mathrm{O}-\mathrm{H}$ bond length obtained from calculations for the isolated $\mathrm{Mg}\left(\mathrm{H}_{2} \mathrm{O}\right)_{6}{ }^{2+}$ complex. The experimental $\mathrm{O}(6)-\mathrm{H}(16)$ bond length in struvite amounting to $0.952 \AA^{31}$ is even slightly shorter than the bond length in vapor water which is $0.958 \AA{ }^{50}$ This is the indication that the $\mathrm{H}(16)$ atom is not involved in forming hydrogen bonds. While all four $\mathrm{P}-\mathrm{O}$ bonds in the phosphate

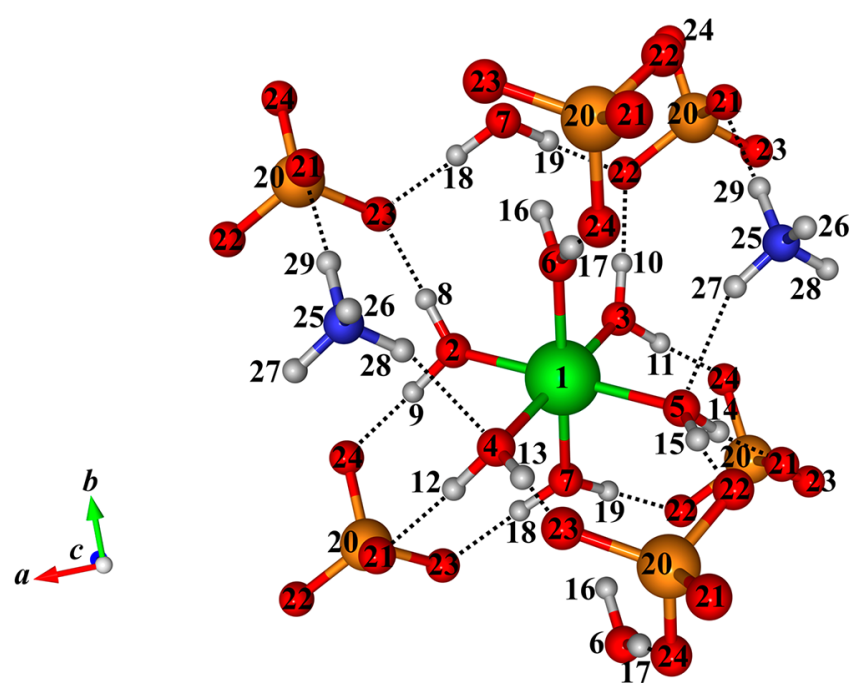

Figure 2. Fragment of struvite crystal structure showing labels assigned to atoms corresponding to the notation used in Tables 2-4. Green, red, blue, orange, and white balls depict positions of $\mathrm{Mg}, \mathrm{O}, \mathrm{N}, \mathrm{P}$, and $\mathrm{H}$ atoms, respectively. Dotted lines connect atoms forming $\mathrm{H}$-bonds. The connection pattern has been established based solely on relative distances between $\mathrm{H}$-bond donors and acceptors. Notice, however, that $\mathrm{H}(16)$ and $\mathrm{O}(7)$ atoms are not connected (see a discussion of the lack of hydrogen bond between these atoms in this work). Picture generated using VESTA ${ }^{47}$ software.

anion in struvite are of similar lengths, one notices, by confronting experimental and theoretical results (see Table 2), that out of four $\mathrm{N}-\mathrm{H}$ bonds in the $\mathrm{NH}_{4}^{+}$cation the $\mathrm{N}-\mathrm{H}(29)$ bond is longer than the other ones. The reason behind it is that $\mathrm{H}(29)$ interacts via $\mathrm{H}$-bonding with the charged oxygen atom belonging to a phosphate group, while the other hydrogen atoms in the $\mathrm{NH}_{4}^{+}$cation interact with the neighboring water molecules. Since oxygen in water molecules bears much smaller negative charge than that of $\mathrm{O}$ in the phosphate anion, the $\mathrm{N}-\mathrm{H}(26),-\mathrm{H}(27)$, and $-\mathrm{H}(28)$ bonds are less elongated than $\mathrm{N}-\mathrm{H}(29)$, see Table 2 and ref 31.

Pavlov et al. $^{48}$ have discussed the nature of the $\mathrm{Mg}-\mathrm{O}$ interaction in the isolated $\mathrm{Mg}\left(\mathrm{H}_{2} \mathrm{O}\right)_{6}{ }^{2+}$ complex with and without the second solvation shell. It has been shown that the $\mathrm{Mg}-\mathrm{O}$ interaction is dominated by electrostatic and induction energy components although the charge transfer also plays a role. The mainly noncovalent character of the $\mathrm{Mg}-\mathrm{O}$ interaction, characterized by low oxygen to magnesium charge transfer, does not change when the $\mathrm{Mg}\left(\mathrm{H}_{2} \mathrm{O}\right)_{6}{ }^{2+}$ complex is part of the struvite crystal. Indirect confirmation is provided by no significant difference in $\mathrm{O}-\mathrm{Mg}$ charge transfer when one compares the isolated $\mathrm{Mg}\left(\mathrm{H}_{2} \mathrm{O}\right)_{6}{ }^{2+}$ complex and the struvite crystal. This can be seen in Table 3 showing Mulliken atomic charges ${ }^{49}$ on $\mathrm{Mg}, \mathrm{O}$, and $\mathrm{H}$ atoms in the crystal and the isolated complex. Charges for the latter are presented in two variants: for the complex in the optimized geometry and in geometry optimized for the crystal. In all three cases charges on magnesium atom are of similar values. The charges on oxygen atoms $\mathrm{O}(2), \mathrm{O}(3), \mathrm{O}(4), \mathrm{O}(5)$, and $\mathrm{O}(7)$ surrounding $\mathrm{Mg}$ obtained from calculations for the crystal structure and equal to ca. -0.8 are larger than those following from predictions for the isolated complex. In the latter case the charges amount to ca. -0.7 , see the last two columns in Table 3 . This is due to the polarization effect of the hydrogen bonds formed in the crystal leading to increasing the charge on the oxygen atoms in water 
(a)

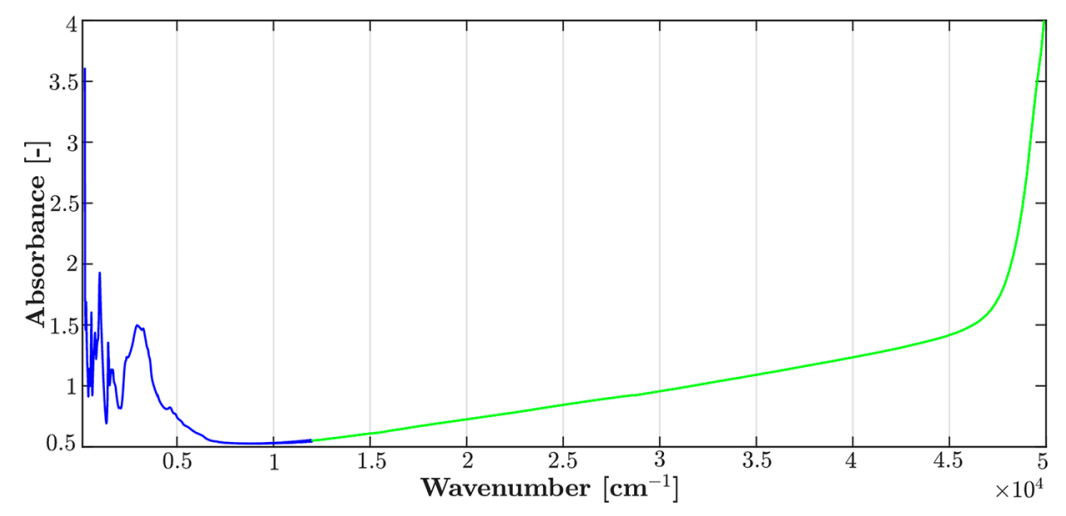

(b)

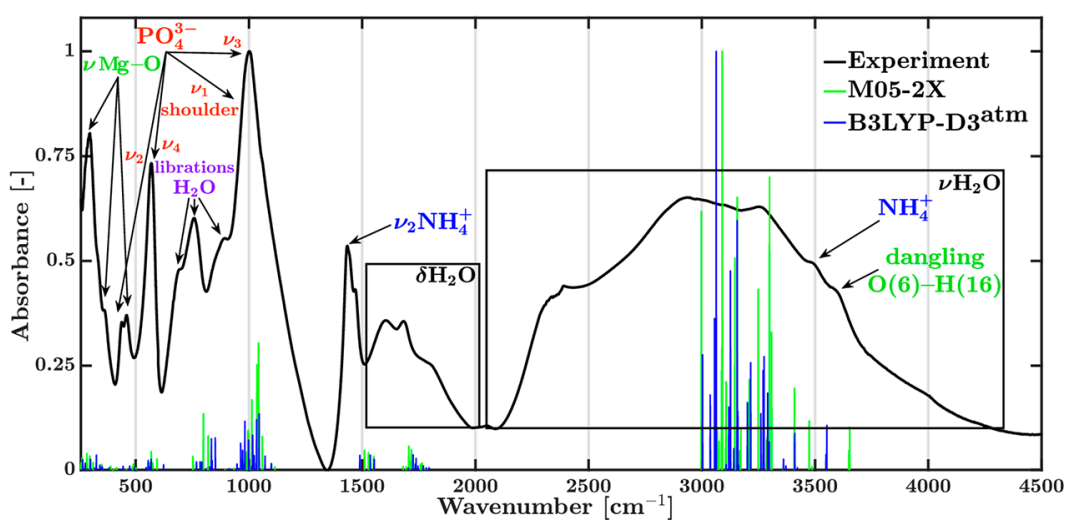

Figure 3. (a) Experimentally obtained spectrum of struvite in broad spectral range: from 200 to $50000 \mathrm{~cm}^{-1}(0.2-50 \mu \mathrm{m})$. Blue line (range up to $12000 \mathrm{~cm}^{-1}$ ) corresponds to the measurements done with use of FTIR instrument, while the green line to data collected with use of UV-vis spectrometer. (b) Comparison of theoretically and experimentally obtained IR spectra of struvite. Theoretically obtained vibrational frequencies assume harmonic approximation. Spectral regions with characteristic fundamental absorption bands of $\mathrm{Mg}-\mathrm{O}, \mathrm{PO}_{4}{ }^{3-}, \mathrm{NH}_{4}{ }^{+}$, and $\mathrm{H}_{2} \mathrm{O}$ are indicated. The blue-shifted stretching mode for the dangling $\mathrm{O}(6)-\mathrm{H}(16)$ bond is also indicated.

molecules comparing to the isolated complex. Notice that the charge on the $\mathrm{O}(6)$ atom in struvite is slightly smaller than charges on the other oxygen atoms. This effect is small but visible and evidently cannot be explained by geometry, cf. Table 2. Rather, this indicates that the polarizing effect of the hydrogen bonds is weaker in the case of the $\mathrm{H}_{2} \mathrm{O}(6)$ molecule than in the case of the other water molecules surrounding $\mathrm{Mg}$ (if the polarization effect is measured by the increase in charge on oxygen when moving from the isolated complex to a complex in crystal then for $\mathrm{O}(6)$ this increase, amounting to 0.07 , is only half of that for the other oxygen atoms, the charge on which increases by ca. 0.14$)$. This is another indication that $\mathrm{H}_{2} \mathrm{O}(6)$ water molecule is not as strongly $\mathrm{H}$-bound with the surrounding species as the other water molecules. The polarizing effect of the hydrogen bonds is responsible not only for increasing the charges on oxygen atoms but it also alters the $\mathrm{Mg}-\mathrm{O}$ bond lengths. ${ }^{48}$ The main effect is the $\mathrm{Mg}-\mathrm{O}$ distance shortening if the respective $\mathrm{H}_{2} \mathrm{O}$ molecule is $\mathrm{H}$-bond proton donating. The possible accompanying trans-effect leads to the increase in the $\mathrm{Mg}-\mathrm{O}$ distance when the oxygen atom belongs to water molecule forming a weak or no H-bond. ${ }^{48}$ This may be the explanation of the relative long $\mathrm{Mg}-\mathrm{O}(6)$ distance, cf. Table 2, since as it has been already indicated the $\mathrm{H}_{2} \mathrm{O}(6)$ is less $\mathrm{H}$-bound than its counterparts. It is not clear why the $\mathrm{Mg}-\mathrm{O}(7)$ bond is also elongated even though the $\mathrm{H}_{2} \mathrm{O}(7)$ forms strong $\mathrm{H}$ bond. One of the possible explanations may be a steric effect.
Since the $\mathrm{H}_{2} \mathrm{O}(2)$ and $\mathrm{H}_{2} \mathrm{O}(3)$ water molecules are closer to the magnesium ion when present in the struvite crystal than in the isolated $\mathrm{Mg}\left(\mathrm{H}_{2} \mathrm{O}\right)_{6}{ }^{2+}$ complex (cf. Table 2) they may be pushing the $\mathrm{H}_{2} \mathrm{O}(7)$ molecule away from the $\mathrm{Mg}$ atom.

Based on experimentally determined bond lengths and large thermal motion of $\mathrm{H}(16)$ Ferraris et al. ${ }^{31}$ concluded that $\mathrm{H}(16)$ forms weak but effective hydrogen bond. Thus, data and its interpretation provided in ref 31 suggest that the frequency of the $\mathrm{O}(6)-\mathrm{H}(16)$ stretching mode will be shifted toward higher values. Below we show that, contrarily to conclusion of Ferraris et al. that $\mathrm{H}(16)$ forms effective $\mathrm{H}$-bond, $\mathrm{H}(16)$ does not form hydrogen bond with the neighboring oxygen atom and $\mathrm{O}(6)-$ $\mathrm{H}(16)$ is a "dangling" group. Strong evidence supporting this claim results from analysis of water binding energies. The binding energy analysis presented in Table 4 has been obtained by assuming pairwise contributions to the interaction energy, neglecting higher than two-body interactions. Counterpoise correction procedure ${ }^{51}$ was applied to remove the basis set superposition error. The binding energies of water molecules in the struvite crystal have been obtained by carrying out three computations. First, the energy of a unit cell of struvite crystal (containing full $\mathrm{Mg}\left(\mathrm{H}_{2} \mathrm{O}\right)_{6}{ }^{2+}$ complex) was obtained. Then, the unit cell energy for the crystal with one water molecule replaced by the corresponding ghost atoms was found. Finally, the energy of a single water molecule was computed by keeping the water molecule of interest in the unit cell and replacing all other 
molecules by the pertinent ghost atoms. Geometry was kept frozen in all calculations. The binding energy followed by subtracting the energy of water and of the crystal without water molecules from the energy of the struvite crystal. The binding energies for water molecules in the crystal are given in the second column of Table 4. For the isolated complex, the binding energies have been obtained as the difference between the energy of the $\mathrm{Mg}\left(\mathrm{H}_{2} \mathrm{O}\right)_{6}{ }^{2+}$ complex and the sum of the energies of the $\mathrm{Mg}\left(\mathrm{H}_{2} \mathrm{O}\right)_{5}{ }^{2+}$ complex and one water molecule. Similarly, to the calculations for the crystal, a counterpoise correction was applied and the unrelaxed geometries (corresponding to the optimized geometry of struvite) were used. All computations have been performed by using the M05-2X functional, which has been found to yield most accurate results for struvite crystal structure, as it has been already discussed. To validate M05-2X results, binding energies for the isolated complex have been also computed using the accurate DFT-SAPT ${ }^{18-22}$ method, using the same geometry of the complex and water molecule as in M05-2X calculations. The results for binding energies of water molecules in the isolated complex are presented in the third and fourth columns of Table 4, respectively. M05-2X values obtained for the isolated complex qualitatively parallel those predicted by DFT-SAPT, which allows one to consider the M05-2X predictions as reliable. Both approaches predict the $\mathrm{H}_{2} \mathrm{O}(6)$ water molecule as the most strongly bound in the isolated complex and the binding energy being ca. $4 \mathrm{kcal} / \mathrm{mol}$ greater than that of the least bound $\mathrm{H}_{2} \mathrm{O}(7)$ molecule.

According to M05-2X prediction, the $\mathrm{H}_{2} \mathrm{O}(6)$ water molecule, the binding energy of which is the largest for the isolated complex, appears to be most weakly bound in the struvite crystal, cf. Table 4. This immediately implies that $\mathrm{H}$ bonds formed by this molecule are weaker than in the case of the other water molecules. The estimation of the total hydrogen bonds energy for each water molecule, shown in the last column of Table 4, have been obtained by subtracting a binding energy of a given water molecule in an isolated $\mathrm{Mg}\left(\mathrm{H}_{2} \mathrm{O}\right)_{6}{ }^{2+}$ complex from the binding energy for the same water molecule in the crystal. It is striking that the $\mathrm{H}$-bond energy for the $\mathrm{H}_{2} \mathrm{O}(6)$ molecule is roughly half of those corresponding to the other water molecules. This is a strong indication that only one hydrogen atom in $\mathrm{H}_{2} \mathrm{O}(6)$ is involved in forming hydrogen bonds, while in the case of the other water molecules both $\mathrm{H}$ atoms form hydrogen bonds. This finding stays in a perfect agreement with evidence that the $\mathrm{H}(16)$ atom connected with $\mathrm{O}(6)$ is not involved in the $\mathrm{H}$-bond formation.

The consequence of the fact that the hydrogen atom $\mathrm{H}(16)$ does not form a hydrogen bond with the neighboring $\mathrm{H}_{2} \mathrm{O}(7)$ water molecule (see Figure 2, where atoms $\mathrm{H}(16)$ and $\mathrm{O}(7)$ are not connected) and, consequently, that the $\mathrm{O}(6)-\mathrm{H}(16)$ is a "dangling" bond, is the expected blueshift in the IR spectrum discussed in the next section. The phenomenon of a blueshift occurring for the $\mathrm{OH}$ dangling groups has been reported in the literature for water at hydrophobic interfaces. ${ }^{52}$

\section{IR SPECTRUM ANALYSIS}

The normalized experimental spectrum of struvite in broad range of wavelengths is shown in Figure 3a. Figure $3 b$ presents the IR spectra obtained by using M05-2X and B3LYP-D3 ${ }^{\text {atm }}$ functionals. They are superimposed on the experimentally obtained spectrum for comparison.

Some characteristic regions in the IR spectrum can be distinguished. The band with the maximum at $298 \mathrm{~cm}^{-1}$ and the line at $360 \mathrm{~cm}^{-1}$ can be assigned to $\nu \mathrm{Mg}-\mathrm{O}$ modes. ${ }^{53,54}$ These modes engage the whole $\mathrm{Mg}-\mathrm{OH}_{2}$ system, namely positions of whole water molecules vary with respect to $\mathrm{Mg}$ (see also the Supporting Information for the CRYSPLOT ${ }^{55}$ visualization of one of the $\nu \mathrm{Mg}-\mathrm{O}$ modes). The description of two lines located at 439 and $460 \mathrm{~cm}^{-1}$ is not unequivocal, due to the fact that both are insensitive to deuterium-substitution. ${ }^{56}$ Thus, according to Stefov et al., they can be assigned to $\nu \mathrm{Mg}-\mathrm{O}$ and/or $\nu_{2}\left(\mathrm{PO}_{4}\right)$ (symmetric bending mode). ${ }^{56}$ However, the spectroscopic studies done on $\mathrm{Mg}(\mathrm{OH})_{2}$ strongly suggest that the line at $460 \mathrm{~cm}^{-1}$ can be attributed to the $\mathrm{Mg}-\mathrm{O}$ mode. ${ }^{53,54}$ The strong, narrow line at $570 \mathrm{~cm}^{-1}$ can be assigned to $\nu_{4}\left(\mathrm{PO}_{4}\right)$ antisymmetric bending mode. This assignment is confirmed by theoretically predicted spectra, since the M05-2X-predicted mode corresponding to $562 \mathrm{~cm}^{-1}$ is a bending mode of the phosphate group. Bands visible below $500 \mathrm{~cm}^{-1}$ have been assigned to stretching and bending $\mathrm{Mg}-\mathrm{O}$ vibrations, and the assignment has been confirmed by visualizing theoretically obtained vibrations in the low-frequency range.

The broad band with the maximum at $1003 \mathrm{~cm}^{-1}$ with the low-energy shoulder relates to overlapping $\nu_{1}\left(\mathrm{PO}_{4}\right)$ (symmetric) and $\nu_{3}\left(\mathrm{PO}_{4}\right)$ (antisymmetric) stretching modes. ${ }^{56}$ These modes have been used to analyze the coordination environment of $\mathrm{PO}_{4}{ }^{3-}$ ions. ${ }^{57}$ Although, originally the analysis was used to study amorphous (glassy) materials, it seems to be also adequate to investigate short-range interactions between $\mathrm{PO}_{4}{ }^{3-}$ and counterions in crystals. In crystal phosphates $\mathrm{PO}_{4}$ tetrahedra form either $\mathrm{P}-\mathrm{O}-\mathrm{P}$ bridges or they are present as isolated groups. This leads to variation in $\mathrm{P}-\mathrm{O}$ bond lengths and the neutron diffraction experiment leads to observing two $\mathrm{P}-\mathrm{O}$ peaks in real-space correlation function. ${ }^{57}$ In struvite crystal, however, the phosphate groups do not form $\mathrm{P}-\mathrm{O}-\mathrm{P}$ bridges but they are present only as isolated $\mathrm{PO}_{4}{ }^{3-}$ ions and the $\mathrm{P}-\mathrm{O}$ bond lengths shown in Table 2, ranging from 1.544 to $1.551 \AA$, are close to the $\mathrm{P}-\mathrm{O}$ distance in sodium phosphate amounting to $1.547 \AA$, where only terminal oxygen atoms are present and there are no bridging $\mathrm{P}-\mathrm{O}$ bonds. ${ }^{58} \mathrm{~A}$ well-defined IR spectral pattern with four characteristic fundamental modes $\nu_{1}, \nu_{2}, \nu_{3}$, and $\nu_{4}$ confirms that in struvite the isolated ionic $\mathrm{PO}_{4}{ }^{3-}$ structure dominates. The bridged structures showing up in the IR spectra in the lower-frequency range, ${ }^{59}$ which could result from dislocations or defects in the crystal structure of struvite, are not visible in the IR spectrum in Figure $2 \mathrm{a}$. A broad highfrequency shoulder accompanying the $1003 \mathrm{~cm}^{-1}$ line and extending until $1350 \mathrm{~cm}^{-1}$ arises from the fact that phosphate tetrahedrons in struvite are surrounded by counterions $\left(\mathrm{NH}_{4}{ }^{+}\right.$ and $\left.\mathrm{Mg}\left(\mathrm{H}_{2} \mathrm{O}\right)_{6}{ }^{2+}\right)$ with delocalized positive charge. Phosphate anion interacts directly only with hydrogens of water or ammonium by forming hydrogen bonds and electrostatically.

The IR bands related to water vibrations are in three regions as follows: between 600 and $1000 \mathrm{~cm}^{-1}$ (librations), 1600-1700 $\mathrm{cm}^{-1}$ (bending, $\delta \mathrm{H}_{2} \mathrm{O}$ ), and 2000-4200 $\mathrm{cm}^{-1}$ (stretching, $\nu \mathrm{H}_{2} \mathrm{O}$ ). Discrete character of these bands clearly shows that the water molecules in struvite are not equivalent and experience different interaction with the neighboring molecules. Stefov et al., ${ }^{56}$ based on comparison of IR and Raman spectra, temperature dependence of individual bands and deuterium substitution, distinguished at least 6 bands related to water librations located at $897,862,783,766,722$, and $710 \mathrm{~cm}^{-1}$, respectively. They overlap each other and overlap also with lines assigned to $\mathrm{PO}_{4}$ tetrahedra making the spectral analysis difficult. It is necessary to underline that the mentioned lines are not fully separated at room temperature and in case of presented herein 
a)
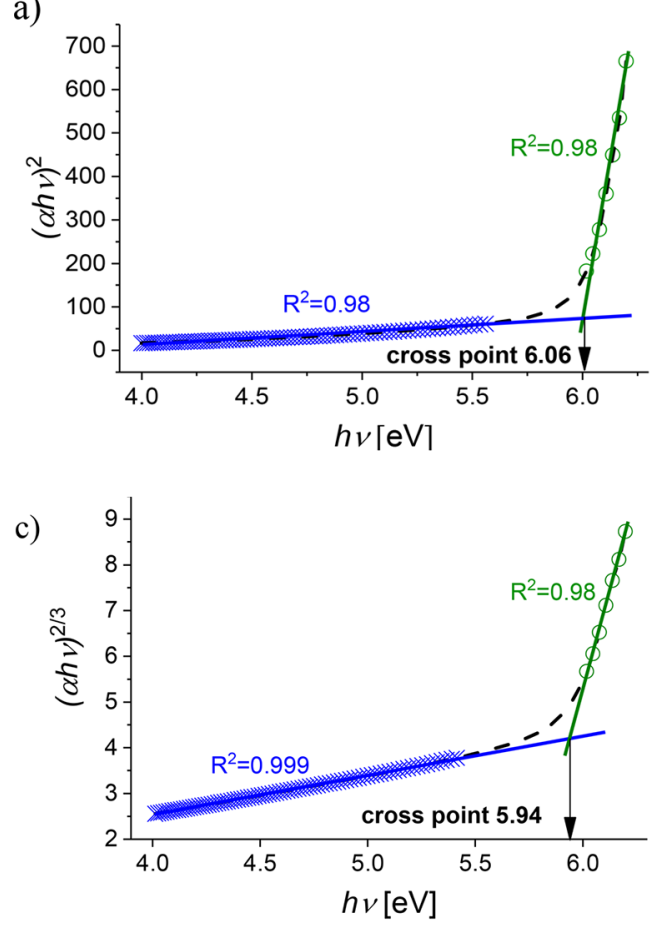

b)
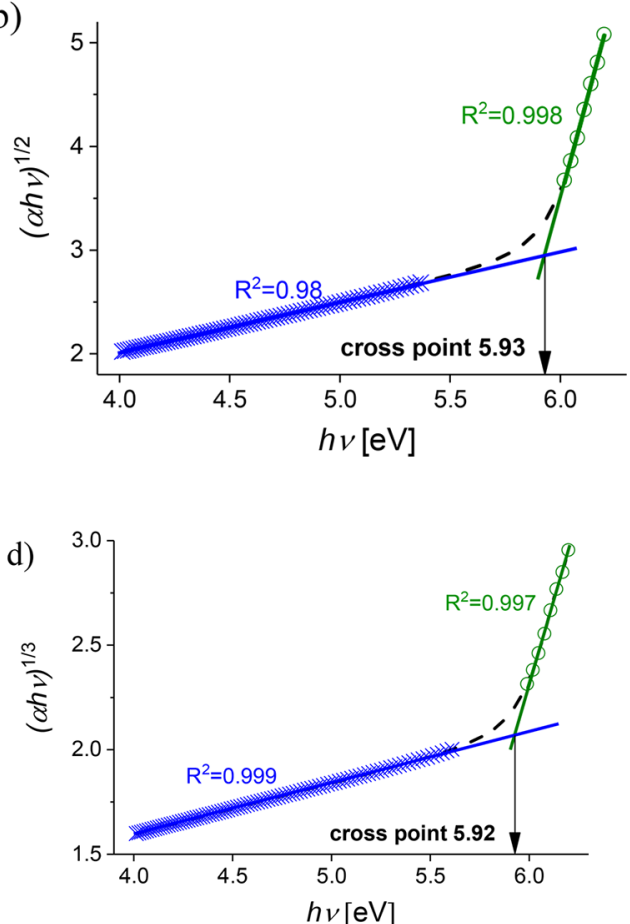

Figure 4. Tauc plots for (a) allowed direct, (b) allowed indirect, (c) forbidden direct, and (d) forbidden indirect possible transitions in struvite.

studies the following lines are visible: 697,759 , and 895 with the shoulder at $850 \mathrm{~cm}^{-1}$.

The $\nu_{2}$ and $\nu_{4} \mathrm{NH}_{4}^{+}$modes in many solid materials give bands at $1399-1402$ and $1630-1625 \mathrm{~cm}^{-1} \cdot{ }^{60-62}$ In struvite the bands assigned to these vibrations are shifted toward higher frequencies due to $\mathrm{H}$-bonds between the ammonia cation and neighborhood water molecules as well as phosphate tetrahedron. In case of $\nu_{2}$ mode, vibrational band is cleaved into two lines: 1434 and $1469 \mathrm{~cm}^{-1}$. Also, the band(s) related to $\nu_{4}$ mode of ammonia is shifted to higher wavenumbers, however, its real position is difficult to find due to the strong overlapping with $-\mathrm{OH}$ bending modes. The main, well-defined lines at 1604 , $1683 \mathrm{~cm}^{-1}$ may be attributed to both $\mathrm{H}-\mathrm{N}-\mathrm{H}$ as well as $\mathrm{H}-\mathrm{O}-$ $\mathrm{H}$ bending modes. Additional broad shoulder at ca. $1790 \mathrm{~cm}^{-1}$ may be assigned to $\mathrm{H}-\mathrm{O}-\mathrm{H}$ bending, and its broadness suggests some orientational disorder of water molecules in struvite leading to broad distribution of $\mathrm{H}$-bond lengths (strengths).

The band related to water stretching is extremely broad and its shoulder ranges far in near IR region up to $5000 \mathrm{~cm}^{-1}$. The main components of this band are placed at 2380, 2920, 3080, 3250, 3460 , and $3560 \mathrm{~cm}^{-1}$. Discrete structure of these bands confirms various water states in struvite. For bulk water the bending and stretching vibrations are located between 1500-1700 (with maximum at $1640-1650 \mathrm{~cm}^{-1}$ ) and $2700-3800 \mathrm{~cm}^{-1}$, respectively. The positions of the water bands in struvite shifted to lower wavenumbers in relation to bulk water may be easily explained by strong interactions with neighborhood. In spite of broad discussion on the water supramolecular structure, it is commonly accepted that the stronger water interacts with an environment, the bigger shift of stretching modes toward lower wavenumbers. ${ }^{63}$ The analysis of the $\mathrm{NH}_{4}^{+}$stretching modes is practically impossible. The corresponding bands overlap with $-\mathrm{OH}$ stretching modes.
The IR spectrum of struvite is characterized by a shift of bending and stretching $\mathrm{O}-\mathrm{H}$ modes toward higher frequency the tail of the $\mathrm{OH}$ stretching band reaches $4500 \mathrm{~cm}^{-1}$. We attribute this shift to the presence of the dangling $\mathrm{O}(6)-\mathrm{H}(16)$ bond in the $\mathrm{H}_{2} \mathrm{O}(6)$ molecule (cf. section 4 where it is shown that $\mathrm{H}(16)$ is not $\mathrm{H}$-bonded with the environment). The lines at 3666 and $3552 \mathrm{~cm}^{-1}$ predicted by the M05-2X and B3LYP$\mathrm{D} 3^{\mathrm{atm}}$ functionals, respectively, have been inspected and they correspond to the $\mathrm{O}(6)-\mathrm{H}(16)$ stretching mode (see also the Supporting Information). We conjecture that the stretching of the dangling $\mathrm{OH}$ group is visible in the measured spectra as a line positioned at $3560 \mathrm{~cm}^{-1}$, and it is a characteristic line of struvite.

It is instructive to note that employing the fitting function of Libowitzky $^{64}$ (which correlates measured $\mathrm{OH}$ stretching frequencies with the oxygen-oxygen distances) with the adequate $\mathrm{O}(6)-\mathrm{O}(7)$, cf. Figure 2, distance of $3.141 \AA$ taken from Ferraris et al. ${ }^{31}$ work, one obtains the $\mathrm{O}(6)-\mathrm{H}(16)$ stretching frequency amounting to $3575 \mathrm{~cm}^{-1}$. The proximity of this value to the frequency of $3560 \mathrm{~cm}^{-1}$ observed in the experimental IR spectrum of struvite could be used as a hint that the observed line might originate from the $\mathrm{O}(6)-\mathrm{H}(16)$ stretching but it should be taken with caution. The reasons are that the correlation function is less reliable in the high-frequency region, where it is practically flat, due to effects not related to $\mathrm{H}$ bonding. ${ }^{64}$ Second, the expected $\mathrm{O}(6)-\mathrm{H}(16)$ stretching mode could be masked by a broad overlapping $\mathrm{NH}_{4}{ }^{+}$stretching and invisible in the measured IR spectrum. The agreement of the frequency predicted by the correlation function with the observed one should be then viewed not as a decisive evidence but another argument confirming our assignment based on theoretical analysis. 


\section{EXPERIMENTAL DETERMINATION OF STRUVITE OPTICAL BANDGAP}

The bandgap of struvite is studied by analyzing the UV-vis spectrum shown in Figure 3a. Wavenumber values greater than $10^{4} \mathrm{~cm}^{-1}$ satisfy the following relationship provided by Tauc: ${ }^{65,66}$

$$
\alpha h \propto\left(h \nu-E_{g}\right)^{n}
$$

where $\alpha$ is the absorption coefficient, $h v$ is the photon energy ( $h$ is the Planck's constant and $v$ is the optical frequency), and $E_{\mathrm{g}}$ is the optical bandgap energy. The exponent $n$ depends on the type of transition and can be equal to $1 / 2,2,3 / 2$, and 3 for the following transitions: allowed direct, allowed indirect, forbidden direct, and forbidden indirect, respectively. The plots of $(\alpha h v)^{1 / n}$ versus photon energy $h v($ in $\mathrm{eV})$, called Tauc plot, ${ }^{67}$ may give information about the character of the observed transition.

In the visible range of light struvite absorbance monotonically increases going from low to high energy range, cf. Figure 3a, green line. This effect is probably due to increasing light scattering on nonhomogeneities present in the studied crystal. This optical inhomogeneities may result from structural defects of struvite crystals. This monotonic increase in absorbance can also indicate that struvite has indirect transitions.

In Figures $4 \mathrm{a}-\mathrm{d}$, Tauc plots are shown for four possible transitions: allowed direct $\left((\alpha h v)^{2}\right)$, allowed indirect $\left((\alpha h v)^{1 / 2}\right)$, forbidden direct $\left((\alpha h v)^{2 / 3}\right)$ and forbidden indirect $\left((\alpha h v)^{1 / 3}\right)$. These plots were obtained in the following way. Struvite spectrum in the range of energy above $4 \mathrm{eV}\left(32262 \mathrm{~cm}^{-1} ; 300\right.$ $\mathrm{nm}$ ) was divided into two parts linear in Tauc representation: between 4.0 and c.a. $5.5 \mathrm{eV}$ (baseline) and above $6.05 \mathrm{eV}$ corresponding to band edge (the particular ranges were chosen to reach the best linear fitting), as Figure $4 a-d$ shows. Both parts of the spectrum were fitted by the linear function in each representation and next the cross-points were analytically determined. An extrapolation of appropriate exponentiation to the baseline (cross point of the exponentiation and the baseline) gives estimated value of bandgap energy. The obtained data is collected in Table 5 and shown in Figure $4 a-d$. The transition energy values show that struvite is an insulator with high energy bandgap.

Table 5. Values of Bandgap for Struvite for Various Transitions Determined Experimentally Based on Tauc Plots

\begin{tabular}{clc} 
Tauc plot & \multicolumn{1}{c}{ transition } & bandgap energy $[\mathrm{eV}]$ \\
$(\alpha h \nu)^{2}$ vs $h \nu$ & direct allowed & 6.06 \\
$(\alpha h \nu)^{1 / 2}$ vs $h \nu$ & indirect allowed & 5.93 \\
$(\alpha h \nu)^{2 / 3}$ vs $h \nu$ & direct forbidden & 5.94 \\
$(\alpha h \nu)^{1 / 3}$ vs $h \nu$ & indirect forbidden & 5.92 \\
\hline
\end{tabular}

The plots shown in Figure 4 do not allow for conclusive determination of the nature of the bandgap. They show that all four possible transitions should be considered, and the corresponding transition energies values are closely lying, i.e., within $0.2 \mathrm{eV}$. In particular, the estimated direct allowed transition occurs at $6.06 \mathrm{eV}$, while indirect allowed, direct forbidden and indirect forbidden practically overlaps and they center at $5.93 \mathrm{eV}$. The theoretically modeled band structure of struvite, cf. Figure 5 presenting the band structure predicted by the M06-L functional, ${ }^{33}$ does not allow one to discern between direct and indirect transitions due to relative flatness of the valence band. The electronic bandgap predicted by the M06-L functional amounts to $5.4 \mathrm{eV}$ so it is closer to the experimentally determined bandgap energies shown in Table 5 than the other values reported in the literature. ${ }^{68}$ One should notice, however, that M06-L, like other meta-GGA (generalized gradient approximation) functionals, is in general unreliable in predicting optical gaps, ${ }^{69}$ so the observed agreement with the experimental value for struvite must be coincidental.

The experimental value of bandgap energy for struvite of 5.07 $\mathrm{eV}$ was also reported by Bindhu et al. ${ }^{78}$ Unfortunately, the authors did not provide information on the procedure they employed to obtain such a value, which makes it difficult to explain a deviation amounting to about $0.9 \mathrm{eV}$ from bandgap values shown in Table 5.

\section{SUMMARY}

In this work the results of experimental and theoretical study of the structure and optical properties of struvite are presented. Covalent and hydrogen bond patterns and their consequence for a special feature of the IR spectrum of struvite is reported. Experimentally determined IR and UV-vis spectra are compared with the results of theoretical study carried out with the use of density functional methods. The first step in computational study assumed selection of a group of density functionals with a special focus on their reliability in describing noncovalent interactions. They have been used to obtain lattice constants. A comparison with the experimental values (Table 1) has led us to retaining the M05-2X and B3LYP-D3 ${ }^{\text {atm }}$ density functional methods as the most accurate for investigation of properties and molecular interactions in struvite. Both functionals perform accurately not only in prediction of lattice constants (the mean unsigned error for the M05-2X and B3LYP$\mathrm{D} 3^{\mathrm{atm}}$ amounting to 0.014 and $0.026 \AA$, respectively) but also of covalent bond lengths in complexes that struvite crystal comprises. The M05-2X functional has led to obtaining bond lengths differing from the experimental values on average by only 0.009 Å. Further studies have been carried out using this functional. Examination of the interatomic bond lengths, Mulliken atomic charges, and binding energies of water in the $\mathrm{Mg}\left(\mathrm{H}_{2} \mathrm{O}\right)_{6}{ }^{2+}$ complex has allowed us to provide theoretical evidence that $\mathrm{H}_{2} \mathrm{O}$ molecules surrounding magnesium cation in struvite form hydrogen bonds of diverse strength. More importantly, it has been revealed that one water molecule has a dangling $\mathrm{OH}$ bond, a consequence of the fact that the related $\mathrm{H}$ atom is not connected via $\mathrm{H}$-bonds with the environment. $\mathrm{A}$ comparison of the $\mathrm{O}-\mathrm{H}$ bond lengths in water molecules in struvite and in the isolated $\mathrm{Mg}\left(\mathrm{H}_{2} \mathrm{O}\right)_{6}{ }^{2+}$ complex has shown that all but one of the $\mathrm{O}-\mathrm{H}$ bonds are elongated in struvite compared to the isolated complex, an indication of hydrogen bonds formation. The bond of one $\mathrm{O}-\mathrm{H}$ group, labeled as $\mathrm{O}(6)-\mathrm{H}(16)$, cf. Figure 2, is not elongated. Analysis of Mulliken charges on oxygen atoms (Table 3 ) leads to a conclusion that the polarizing effect of $\mathrm{H}$-bonds, ${ }^{48}$ leading to greater charges on oxygen atoms in water molecules acting as proton donors, is practically not observed in the case of the $\mathrm{H}_{2} \mathrm{O}(6)$ molecule. It has strengthened the presumption that the $\mathrm{H}(16)$ atom is not $\mathrm{H}$ bond connected. The final argument is provided by estimation of $\mathrm{H}$-bond binding energies for each water molecule in the crystal (Table 4). We have found out that the energy of $\mathrm{H}$-bonds formed by the $\mathrm{H}_{2} \mathrm{O}(6)$ molecule is roughly twice as low as found for the other water molecules bound with the magnesium cation. We have conjectured that only one $\mathrm{H}$ atom in $\mathrm{H}_{2} \mathrm{O}(16)$ acts as a $\mathrm{H}$-bond donor, while the other one does not interact with the environment, forming a "dangling" hydroxyl group. 


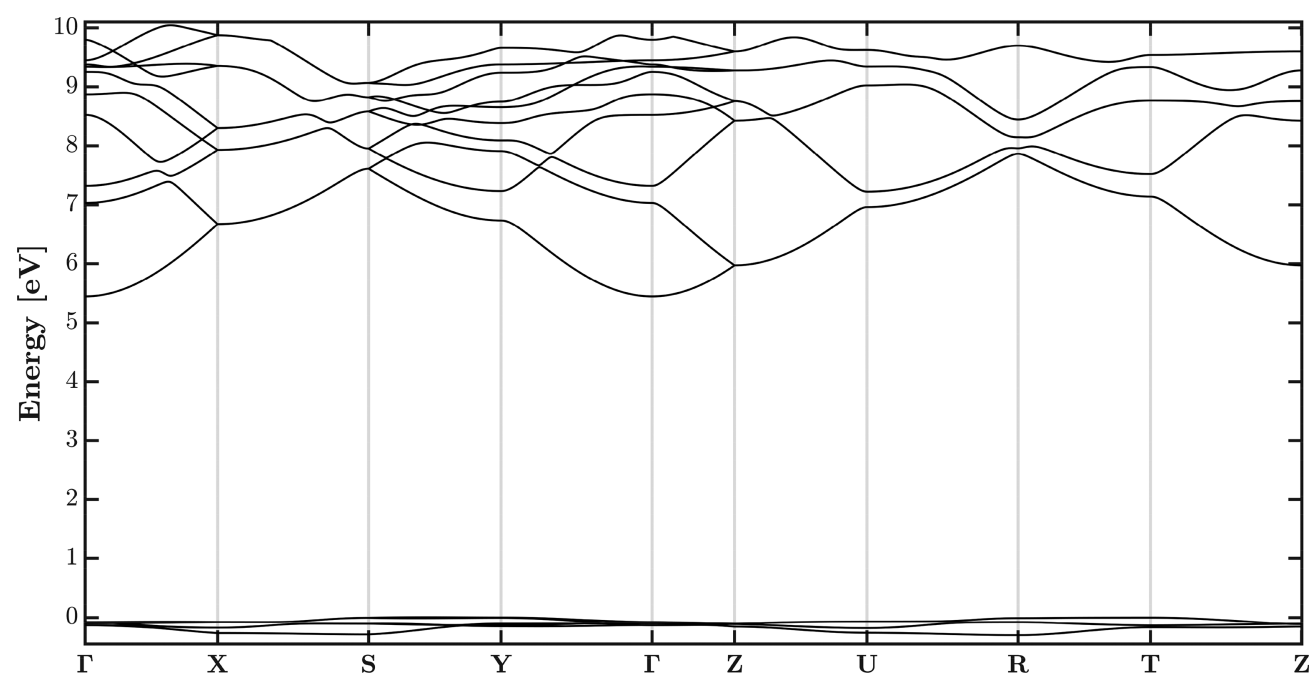

Figure 5. Band structure of struvite computed with the M06-L density functional.

The experimental IR spectrum has been obtained for the home-grown struvite crystals. The spectrum has been discussed and the main bands are identified and described. The expected consequence of the presence of the dangling $\mathrm{OH}$ group is a blueshift of the band corresponding to the $\mathrm{O}(6)-\mathrm{H}(16)$ stretching mode in the IR spectrum. The line positioned at $3560 \mathrm{~cm}^{-1}$ has been assigned to this mode (Figure $2 \mathrm{~b}$ ) and theoretically obtained vibration spectrum has confirmed this assignment (cf. Supporting Information). This mode is a special feature of the struvite crystal IR spectrum. The other characteristic modes are those assigned to the $\mathrm{Mg}-\mathrm{O}$ stretching modes appearing below $500 \mathrm{~cm}^{-1}$, and the strong, narrow line at $570 \mathrm{~cm}^{-1}$ assigned to the $\mathrm{PO}_{4}$ antisymmetric bending mode.

The UV-vis spectrum, presented in Figure $3 \mathrm{a}$, has been used to obtain Tauc plots. Analysis of the latter has led us to the conclusion that all four possible transitions should be considered, and the optical bandgap of struvite lies in the range from 5.92 to $6.06 \mathrm{eV}$. To the best of our knowledge this is the most accurate estimation of the bandgap of struvite determined thus far.

It should be emphasized that the obtained experimental and theoretical results complement each other perfectly. Some of the results presented, for example the occurrence of "dangling" $\mathrm{OH}$, would not be observable without a combination of experimental and theoretical studies.

\section{ASSOCIATED CONTENT}

\section{SI Supporting Information}

The Supporting Information is available free of charge at https://pubs.acs.org/doi/10.1021/acs.jpca.0c04707.

File with visualization of the $\nu \mathrm{Mg}-\mathrm{O}\left(284 \mathrm{~cm}^{-1}\right)$ mode simulated with M05-2X functional (MP4)

File with visualization of the $\mathrm{O}(16)-\mathrm{H}(6)$ stretching $\left(3666 \mathrm{~cm}^{-1}\right)$ mode simulated with M05-2X functional (MP4)

Optimized geometry of struvite obtained with the M052X functional and detailed information about integration grid used in DFT calculation of the crystal and molecular structures (PDF)

\section{AUTHOR INFORMATION}

\section{Corresponding Author}

Jolanta Prywer - Institute of Physics, Lodz University of Technology, 90-924 Łódź, Poland; (1) orcid.org/0000-00015161-2785; Phone: +48 0426313653 ;

Email: jolanta.prywer@p.lodz.pl

\section{Authors}

Dominik Sidorczuk - Institute of Physics, Lodz University of Technology, 90-924 Łódź, Poland

Marcin Kozanecki - Department of Molecular Physics, Lodz University of Technology, 90-924 Łódź, Poland; (1) orcid.org/ 0000-0001-7400-6315

Bartolomeo Civalleri - Department of Chemistry, University of Torino, 10125 Torino, Italy; orcid.org/0000-0003-31983161

Katarzyna Pernal - Institute of Physics, Lodz University of Technology, 90-924 Łódź, Poland

Complete contact information is available at:

https://pubs.acs.org/10.1021/acs.jpca.0c04707

\section{Notes}

The authors declare no competing financial interest.

\section{ACKNOWLEDGMENTS}

The calculations mentioned in this paper are performed using Lodz University of Technology Computing \& Information Services Center infrastructure. This work was supported by the Ministry of Science and Higher Education (Poland), Grant No. I-3/501/17-3-1-728.

\section{REFERENCES}

(1) Doyle, J. D.; Parsons, S. A. Struvite Formation, Control and Recovery. Water Res. 2002, 36, 3925-3940.

(2) Morse, G.; Brett, S.; Guy, J.; Lester, J. Review: Phosphorus Removal and Recovery Technologies. Sci. Total Environ. 1998, 212, $69-81$.

(3) Booker, N. A.; Priestley, A. J.; Fraser, I. H. Struvite Formation in Wastewater Treatment Plants: Opportunities for Nutrient Recovery. Environ. Technol. 1999, 20, 777-782.

(4) Jaffer, Y.; Clark, T.; Pearce, P.; Parsons, S. Potential Phosphorus Recovery by Struvite Formation. Water Res. 2002, 36, 1834-1842. 
(5) Maqueda, C.; Pérez Rodríguez, J. L.; Lebrato, J. Study of Struvite Precipitation in Anaerobic Digesters. Water Res. 1994, 28, 411-416.

(6) Gaterell, M. R.; Gay, R.; Wilson, R.; Gochin, R. J.; Lester, J. N. An Economic and Environmental Evaluation of the Opportunities for Substituting Phosphorus Recovered from Wastewater Treatment Works in Existing UK Fertiliser Markets. Environ. Technol. 2000, 21, 1067-1084.

(7) Strickland, J. Perspectives for Phosphorus Recovery Offered by Enhanced Biological P Removal. Environ. Technol. 1999, 20, 721-725.

(8) Website of e-medicine (Medscape): Struvite and Staghorn Calculi; http://emedicine.medscape.com/article/439127; accessed 18 December 2019.

(9) Bichler, K.-H.; Eipper, E.; Naber, K.; Braun, V.; Zimmermann, R.; Lahme, S. Urinary Infection Stones. Int. J. Antimicrob. Agents 2002, 19, 488-498.

(10) McLean, R. J. C.; Nickel, J. C.; Cheng, K.-J.; Costerton, J. W.; Banwell, J. G. The Ecology and Pathogenicity of Urease-Producing Bacteria in the Urinary Tract. CRC Critical Reviews in Microbiology 1988, 16, 37-79.

(11) Dovesi, R.; Erba, A.; Orlando, R.; Zicovich-Wilson, C. M.; Civalleri, B.; Maschio, L.; Rerat, M.; Casassa, S.; Baima, J.; Salustro, S.; Kirtman, B. Quantum-Mechanical Condensed Matter Simulations with CRYSTAL. WIREs Comput. Mol. Sci. 2018, 8, No. e1360.

(12) Dovesi, R.; Saunders, V. R.; Roetti, C.; Orlando, R.; ZicovichWilson, C. M.; Pascale, F.; Civalleri, B.; Doll, K.; Harrison, N. M.; Bush, I. J.; D’Arco, P.; Llunell, M.; Causà, M.; Noël, Y.; Maschio, L.; Erba, A.; Rerat, M.; Casassa, S. CRYSTAL17 User's Manual; University of Torino: Torino, 2017.

(13) Peintinger, M. F.; Oliveira, D. V.; Bredow, T. Consistent Gaussian Basis Sets of Triple-Zeta Valence with Polarization Quality for Solid-State Calculations. J. Comput. Chem. 2013, 34, 451-459.

(14) Schäfer, A.; Horn, H.; Ahlrichs, R. Fully Optimized Contracted Gaussian Basis Sets for Atoms Li to Kr. J. Chem. Phys. 1992, 97, 25712577.

(15) Monkhorst, H. J.; Pack, J. D. Special Points for Brillouin-Zone Integrations. Phys. Rev. B 1976, 13, 5188-5192.

(16) Maschio, L.; Kirtman, B.; Orlando, R.; Rèrat, M. Ab Initio Analytical Infrared Intensities for Periodic Systems Through a Coupled Perturbed Hartree-Fock/Kohn-Sham Method. J. Chem. Phys. 2012, 137, 204113.

(17) Dall'Olio, S.; Dovesi, R.; Resta, R. Spontaneous Polarization as a Berry Phase of the Hartree-Fock Wave Function: The Case of $\mathrm{KNbO}_{3}$. Phys. Rev. B: Condens. Matter Mater. Phys. 1997, 56, 10105-10114.

(18) Williams, H. L.; Chabalowski, C. F. Using Kohn-Sham Orbitals in Symmetry-Adapted Perturbation Theory to Investigate Intermolecular Interactions. J. Phys. Chem. A 2001, 105, 646-659.

(19) Heßelmann, A.; Jansen, G. First-Order Intermolecular Interaction Energies from Kohn-Sham Orbitals. Chem. Phys. Lett. 2002, 357, 464-470.

(20) Heßelmann, A.; Jansen, G. Intermolecular Induction and Exchange-Induction Energies from Coupled-Perturbed Kohn-Sham Density Functional Theory. Chem. Phys. Lett. 2002, 362, 319-325.

(21) Heßelmann, A.; Jansen, G. Intermolecular Dispersion Energies from Time-Dependent Density Functional Theory. Chem. Phys. Lett. 2003, 367, 778-784.

(22) Heßelmann, A.; Jansen, G. The Helium Dimer Potential from a Combined Density Functional Theory and Symmetry-Adapted Perturbation Theory Approach Using an Exact Exchange-Correlation Potential. Phys. Chem. Chem. Phys. 2003, 5, 5010-5014.

(23) Werner, H.-J.; Knowles, P. J.; Knizia, G.; Manby, F. R.; Schütz, M. Molpro - a General Purpose Quantum Chemistry Program Package. WIREs Comput. Mol. Sci. 2012, 2, 242-253.

(24) Kendall, R. A.; Dunning, T. H.; Harrison, R. J. Electron Affinities of the First-Row Atoms Revisited. Systematic Basis Sets and Wave Functions. J. Chem. Phys. 1992, 96, 6796-6806.

(25) Woon, D. E.; Dunning, T. H. Gaussian basis sets for use in correlated molecular calculations. III. The Atoms Aluminum Through Argon. J. Chem. Phys. 1993, 98, 1358-1371.
(26) Grüning, M.; Gritsenko, O. V.; van Gisbergen, S. J. A.; Baerends, E. J. Shape Corrections to Exchange-Correlation Potentials by Gradient-Regulated Seamless Connection of Model Potentials for Inner and Outer Region. J. Chem. Phys. 2001, 114, 652-660.

(27) Perdew, J. P.; Burke, K.; Ernzerhof, M. Generalized Gradient Approximation Made Simple. Phys. Rev. Lett. 1996, 77, 3865-3868.

(28) Werner, H.-J.; Schütz, M. An Efficient Local Coupled Cluster Method for Accurate Thermochemistry of Large Systems. J. Chem. Phys. 2011, 135, 144116.

(29) Weigend, F. A Fully Direct RI-HF Algorithm: Implementation, Optimised Auxiliary Basis Sets, Demonstration of Accuracy and Efficiency. Phys. Chem. Chem. Phys. 2002, 4, 4285-4291.

(30) Lias, S. G. Ionization Energy Evaluation. In NIST Chemistry WebBook, NIST Standard Reference Database Number 69; Linstrom, P. J., Mallard, W.G., Eds.; National Institute of Standards and Technology: Gaithersburg, MD, 2020.

(31) Ferraris, G.; Fuess, H.; Joswig, W. Neutron Diffraction Study of $\mathrm{MgNH}_{4} \mathrm{PO}_{4} \cdot 6 \mathrm{H}_{2} \mathrm{O}$ (Struvite) and Survey of Water Molecules Donating Short Hydrogen Bonds. Acta Crystallogr., Sect. B: Struct. Sci. 1986, 42, 253-258.

(32) Zhao, Y.; Schultz, N. E.; Truhlar, D. G. Design of Density Functionals by Combining the Method of Constraint Satisfaction with Parametrization for Thermochemistry, Thermochemical Kinetics, and Noncovalent Interactions. J. Chem. Theory Comput. 2006, 2, 364-382.

(33) Zhao, Y.; Truhlar, D. G. A New Local Density Functional for Main-Group Thermochemistry, Transition Metal Bonding, Thermochemical Kinetics, and Noncovalent Interactions. J. Chem. Phys. 2006, $125,194101$.

(34) Chai, J.-D.; Head-Gordon, M. Systematic Optimization of LongRange Corrected Hybrid Density Functionals. J. Chem. Phys. 2008, 128, 084106.

(35) Becke, A. D. Density-Functional Exchange-Energy Approximation with Correct Asymptotic Behavior. Phys. Rev. A: At., Mol., Opt. Phys. 1988, 38, 3098-3100.

(36) Krukau, A. V.; Vydrov, O. A.; Izmaylov, A. F.; Scuseria, G. E. Influence of the Exchange Screening Parameter on the Performance of Screened Hybrid Functionals. J. Chem. Phys. 2006, 125, 224106.

(37) Grimme, S.; Antony, J.; Ehrlich, S.; Krieg, H. A Consistent and Accurate Ab Initio Parametrization of Density Functional Dispersion Correction (DFT-D) for the 94 Elements H-Pu. J. Chem. Phys. 2010, $132,154104$.

(38) Becke, A. D.; Johnson, E. R. A Density-Functional Model of the Dispersion Interaction. J. Chem. Phys. 2005, 123, 154101.

(39) Grimme, S.; Ehrlich, S.; Goerigk, L. Effect of the Damping Function in Dispersion Corrected Density Functional Theory. J. Comput. Chem. 2011, 32, 1456-1465.

(40) Smith, D. G. A.; Burns, L. A.; Patkowski, K.; Sherrill, C. D. Revised Damping Parameters for the D3 Dispersion Correction to Density Functional Theory. J. Phys. Chem. Lett. 2016, 7, 2197-2203.

(41) Axilrod, B. M.; Teller, E. Interaction of the Van Der Waals Type Between Three Atoms. J. Chem. Phys. 1943, 11, 299-300.

(42) Muto, Y. Force Between Nonpolar Molecules. Proc. Phys. Math. Soc. Jpn. 1943, 17, 629-631.

(43) Prywer, J.; Sieroń, L.; Czylkowska, A. Struvite Grown in Gel, Its Crystal Structure at $90 \mathrm{~K}$ and Thermoanalytical Study. Crystals 2019, 9, 89.

(44) Whitaker, A.; Jeffery, J. W. The Crystal Structure of Struvite, $\mathrm{MgNH}_{4} \mathrm{PO}_{4} \cdot 6 \mathrm{H}_{2} \mathrm{O}$. Acta Crystallogr., Sect. B: Struct. Crystallogr. Cryst. Chem. 1970, 26, 1429-1440.

(45) Abbona, F.; Calleri, M.; Ivaldi, G. Synthetic Struvite, $\mathrm{MgNH}_{4} \mathrm{PO}_{4} \cdot 6 \mathrm{H}_{2} \mathrm{O}$ : Correct Polarity and Surface Features of Some Complementary Forms. Acta Crystallogr., Sect. B: Struct. Sci. 1984, 40, 223-227.

(46) Tansman, G. F.; Kindstedt, P. S.; Hughes, J. M. Minerals In Food: Crystal Structures of Ikaite and Struvite From Bacterial Smears On Washed-Rind Cheese. Can. Mineral. 2017, 55, 89-100.

(47) Momma, K.; Izumi, F. VESTA3for Three-Dimensional Visualization of Crystal, Volumetric and Morphology Data. J. Appl. Crystallogr. 2011, 44, 1272-1276. 
(48) Pavlov, M.; Siegbahn, P. E. M.; Sandström, M. Hydration of Beryllium, Magnesium, Calcium, and Zinc Ions Using Density Functional Theory. J. Phys. Chem. A 1998, 102, 219-228.

(49) Mulliken, R. S. Electronic Population Analysis on LCAO-MO Molecular Wave Functions. I. J. Chem. Phys. 1955, 23, 1833-1840.

(50) Hoy, A. R.; Bunker, P. R. A Precise Solution of the Rotation Bending Schrödinger Equation for a Triatomic Molecule with Application to the Water Molecule. J. Mol. Spectrosc. 1979, 74, 1-8.

(51) Boys, S. F.; Bernardi, F. The Calculation of Small Molecular Interactions by the Differences of Separate Total Energies. Some Procedures with Reduced Errors. Mol. Phys. 1970, 19, 553-566.

(52) Tomobe, K.; Yamamoto, E.; Kojić, D.; Sato, Y.; Yasui, M.; Yasuoka, K. Origin of the blueshift of water molecules at interfaces of hydrophilic cyclic compounds. Sci. Adv. 2017, 3, No. e1701400.

(53) Buchanan, R. A.; Caspers, H. H.; Murphy, J. Lattice Vibration Spectra of $\mathrm{Mg}(\mathrm{OH})_{2}$ and $\mathrm{Ca}(\mathrm{OH})_{2}$. Appl. Opt. 1963, 2, 1147-1150.

(54) De Oliveira, E.; Hase, Y. Infrared Study and Isotopic Effect of Magnesium Hydroxide. Vib. Spectrosc. 2001, 25, 53-56.

(55) Beata, G.; Perego, G.; Civalleri, B. CRYSPLOT: A New Tool to Visualize Physical and Chemical Properties of Molecules, Polymers, Surfaces, and Crystalline Solids. J. Comput. Chem. 2019, 40, 23292338.

(56) Stefov, V.; Šoptrajanov, B.; Spirovski, F.; Kuzmanovski, I.; Lutz, H.; Engelen, B. Infrared and Raman Spectra of Magnesium Ammonium Phosphate Hexahydrate (Struvite) and its Isomorphous Analogues. I. Spectra of Protiated and Partially Deuterated Magnesium Potassium Phosphate Hexahydrate. J. Mol. Struct. 2004, 689, 1-10.

(57) Brow, R. K. Review: The Structure of Simple Phosphate Glasses.

J. Non-Cryst. Solids 2000, 263-264, 1-28.

(58) Hoppe, U.; Kranold, R.; Stachel, D.; Barz, A.; Hannonb, A. C. Variation in P-O Bonding in Phosphate Glasses -A Neutron Diffraction Study. Z. Naturforsch., A: Phys. Sci. 2000, 55, 369-380.

(59) Efimov, A. M. IR Fundamental Spectra and Structure of Pyrophosphate Glasses Along the $2 \mathrm{ZnO} \cdot \mathrm{P}_{2} \mathrm{O}_{5}-2 \mathrm{Me}_{2} \mathrm{O} \cdot \mathrm{P}_{2} \mathrm{O}_{5}$ Join $(\mathrm{Me}$ Being $\mathrm{Na}$ and Li). J. Non-Cryst. Solids 1997, 209, 209-226.

(60) Karray, R.; Kabadou, A.; Ciśařová, I.; Hassen, R. B.; Salah, A. B. Structure of Rubidium-Ammonium Hexachlorotellurate $\left[\mathrm{Rb}_{0.8}(\mathrm{NH} 4)_{0.2}\right]_{2} \mathrm{TeC}_{16}$ at Room and Low Temperatures. J. Alloys Compd. 2004, 377, 85-90.

(61) Berg, R. W.; Poulsen, F. W.; Bjerrum, N. J. Low Temperature Vibrational Spectroscopy. I. Hexachlorotellurates. J. Chem. Phys. 1977, 67, 1829-1837.

(62) Wu, X.; Tao, Y.; Dong, L.; Hong, J. Synthesis and Characterization of Self-Assembling $\left(\mathrm{NH}_{4}\right)_{0.5} \mathrm{~V}_{2} \mathrm{O}_{5}$ Nanowires. J. Mater. Chem. 2004, 14, 901-904.

(63) Novak, A. Hydrogen bonding in Solids Correlation of Spectroscopic and Crystallographic Data. Large Molecules. Structure and Bonding; Springer: Berlin, 1974; Vol. 18, pp 177-216.

(64) Libowitzky, E. Correlation of O-H Stretching Frequencies and O-H - . O Hydrogen Bond Lengths in Minerals. Monatsh. Chem. 1999, 130, 1047-1059.

(65) Wood, D. L.; Tauc, J. Weak Absorption Tails in Amorphous Semiconductors. Phys. Rev. B 1972, 5, 3144-3151.

(66) Davis, E. A.; Mott, N. F. Conduction in Non-Crystalline Systems V. Conductivity, Optical Absorption and Photoconductivity in Amorphous Semiconductors. Philos. Mag. 1970, 22, 0903-0922.

(67) Tauc, J. Optical Properties and Electronic Structure of Amorphous Ge and Si. Mater. Res. Bull. 1968, 3, 37-46.

(68) Piechota, J.; Prywer, J.; Torzewska, A. Ab Initio Predictions of Structural and Elastic Properties of Struvite: Contribution to Urinary Stone Research. Computer Methods in Biomechanics and Biomedical Engineering 2012, 15, 1329-1336.

(69) Pernot, P.; Civalleri, B.; Presti, D.; Savin, A. Prediction Uncertainty of Density Functional Approximations for Properties of Crystals with Cubic Symmetry. J. Phys. Chem. A 2015, 119, 5288-5304.

(70) Bindhu, B.; Swetha, A. S.; Veluraja, K. Studies on the Effect of Phyllanthusemblica Extract on the Growth of Urinary Type Struvite Crystals in Vitro. Clin. Phytoscience 2015, 1, 3. 